\title{
Pengaruh kecerdasan adversitas dan kecerdasan emosional melalui model inkuiri sosial terhadap keterampilan sosial siswa
}

\section{Wardani $^{1}$}

Diterima 23 Mei 2019, Dipublikasikan 31 Oktober 2019

Cpenulis (2019)

\begin{abstract}
The research purpose is to knowing the effect of adversity intelligence and emotional intelligence through social inquiry model against social skill. The research method used ex post facto. The collection data technique using questionnaire. The taking sample technique is approached simple random sampling. The amount of sample is 104 students on SMP N 10 Bandar Lampung. The data analysis using Structural Equation Modeling (SEM). The research result showing that there's a positive relation lickages between endogenous variable, exogenous variable, and intervening variable. Through social inkuiri model, intelligence and emotional intelligence adversitas will play a role effective in improved the skills of social. It would be useful for a student to are learning success in classes and in the future. It is expected that schools can optimize emosial adversitas intelligence and intelligence in order to enhance its social skill and skills students academic. Can be concluded that if adversity intelligence and emotional intelligence through social inquiry model against social skill.
\end{abstract}

Keywords

Adversity Intelligence, Emotional Intelligence, Social Inquiry Model, Social Skill

\section{PENDAHULUAN}

Adversity diartikan sebagai kesengsaraan dan kemalangan yang dianggap menjadi salah satu faktor penentu kesuksesan seseorang (Karimah, 2017). Adversity Intellegence kemampuan menginformasikan dalam menghadapi suatu keadaan atau kesulitan dan kemampuan untuk mengatasinya. Kemampuan individu untuk mampu atau tidak mampu menghadapi kesulitan (Schoon, 2004). Meramalkan kemampuan individu yang akan gagal dan melampui harapan atas kinerja dan potensi yang dimiliki. Meramalkan kemampuan individu yang akan menyerah dan yang dapat bertahan menghadapi kesulitan.

Kecerdasan adversitas diartikan sebagai kecerdasan daya juang seseorang dalam menghadapi berbagai permasalahan. Setidaknya ada 4 (empat) aspek seseorang mempunyai kecerdasan adversitas untuk dapat memperkirakan, seperti (1) kemampuan seseorang bertahan menghadapi kesulitan dan mengatasi permasalahan yang dihadapi, (2) kemampuan memperkirakan batas waktu seseorang mengatasi kesulitan dan akan menyerah pada kesulitan, (3) kemampuan sejauh mana seseorang dapat melampaui harapan-harapan atas kinerja dan potensi setiap individu, dan (4) kemampuan memperkirakan seseorang akan menyerah pada kesulitan yang dihadapinya (Hartosujono, 2015).

1 Jurusan Tadris IPS Institut Agama Islam Negeri (IAIN) Metro Lampung muhammad.wardani1990@gmail.com 
Setiap individu mempunyai keinginan untuk sukses dalam berbagai hal sesuai dengan tujuan hidupnya. Untuk mencapai sukses tersebut butuh ketahanan diri, kemampuan untuk bangkit kembali, dan sifat yang tidak mudah menyerah dalam mencapai tujuan (Zaim, 2016). Ketangguhan seseorang menghadapi berbagai kesulitan tersebut yang disebut sebagai kecerdasan adversitas (Shivinder dan Kaur, 2012)

Tidak sedikit orang beranggapan bahwa kecerdasan otak yang dianggap paling penting. Kecerdasan otak lebih mengarah padah perolehan hasil belajar anak (Wijayanti, 2012). Bahkan orang tua harus mengeluarkan banyak uang untuk mendaftarkan anaknya ke bimbingan belajar atau privat mata pelajaran agar memperoleh prestasi belajar yang baik. Banyak orang beranggapan bahwa kecerdasan otak atau outputnya hasil belajar merupakan satu-satunya jalan menuju kesuksesan, sedangkan kemampuan yang lainya dianggap kurang penting. Namun akhir-akhir ini diyakini sebagai revolusi industri 4.0 keyakinan tersebut telah disanggah dengan berbagai macam bukti. Hal yang menentukan kesuksesan seseorang bukan kecerdasan intelektual, tetapi lebih pada kecerdasan adversitas dan kecerdasan emosional (Prawitasari, 1998). Dianggap bahwa kecerdasan otak bergantung pada faktor genetik dan sulit untuk diubah, namun tidak demikian dengan kecerdasan adversitas dan kecerdasan emosional yang dapat diubah untuk meraih sukses kehidupan. Hal tersebut selaras dengan pendapat Golemen (dalam Theda, 2018) yang menyatakan bahwa kecerdasan intektual yang sering disebut dengan IQ merupakan kecerdasan yang dibangun oleh otak kiri. Kecerdasan intelektual (Apriyanti, 2014; Choiriah, 2013; Floretta, 2014) hanya mampu menyumbang 20 persen kesuksesan dan 80 persen berasal dari kekuatan-kekuatan lain termasuk kecerdasan adversitas dan kecerdasan emosional. Kecerdasan intelektual dibutuhkan untuk melakukan aktivitas mental berpikir, menalar, dan memecahkan masalah. Sedangkan kecerdasan adversitas dan kecerdasan emosional dibutuhkan seseorang agar mampu mengenali persaan diri sendiri dan orang lain serta mampu mengelola emosi (Husnurrosyah, 2015).

Berdasarkan hasil penelitian Daniel Goleman menyatakan bahwa kegagalan sering dialami oleh orang ber-IQ tinggi, sedangkan kesuksesan sering diperoleh orang yang mempunyai IQ sedang (Gitosaroso, 2012). Kemungkinan hal tersebut dapat terjadi karena orang yang mempunyai IQ sedang lebih mampu mengendalikan diri, semangat dan tekun serta mampu mempunyai motivasi yang tinggi. Kecerdasan emosional menunjukan kemampuan seseorang memahami perasaan diri sendiri, memahami perasaan orang lain, mampu memotivasi diri sendiri dan mampu memotivasi orang lain. Peningkatan kecerdasan adversitas dan kecerdasan emosional diduga dapat berubah setelah menerima perlakuan dari inkuri sosial. Inkuiri sosial merupakan manifestasi dari model pembelajaran ikuiri yang berorientasi interaksi sosial antar individu (Wahab, 2007). Inkuiri sosial hadir sebagai upaya untuk memperbaiki hubungan interpersonal antar masyarakat yang saat ini mulai tumbuh intoleransi yang tinggi dengan melalui jalan demokratis. Inkuiri sosial berupaya untuk merefleksikan solusi menangani berbagai informasi dalam bentuk konsep dan nilai-nilai. Pemikiran reflektif akan mampu meningkatkan konsep pola pikir suatu masyarakat.

Inkuiri sosial merupakan suatu model yang memberi kesempatan kepada siswa untuk berdiskusi dalam iklim yang terbuka. Diskusi berorientasi solusi yang bersifat hipotetik (Salam, 2017). Pengetahuan dianggap sebagai hipotesis yang akan diuji secara terus menerus. Siswa dan guru memperoleh data dari berbagai sumber untuk dianalisis. Hasil yang diharapkan siswa akan terbentuk karakternya melalui fakta-fakta yang tervalidasi secara ilmiah. 
Keterampilan sosial merupakan bagian dari life skills yang mempunyai beberapa indikator, antara lain (1) keterampilan berkomunikasi, (2) keterampilan menulis, (3) keterampilan bekerjasama, dan (4) keterampilan mengendalikan konflik atau empati (Depdiknas, 2007). Keterampilan individu untuk mengendalikan konflik dapat disamakan dengan aspek kerjasama berpartisipasi (Usman, 2006). Keterampilan sosial dapat diartikan sebagai keterampilan interpersonal (Ardana, 2013). Keterampilan interpersonal sangat penting melatih individu menyusun jaringan (network) yang lebih luas (Scott, 2010). Salah satu cara untuk meningkatkan keterampilan sosial dengan cara belajar bersama teman-teman (Lwin, et al., 2008).

Kerjasama dalam bentuk komunikasi lisan dan tulisan merupakan pembelajaran kontektual yang sangat penting terutama menghilangkan hambatan mental dengan cara menghilangkan terbatasnya pengalaman dan cara pandang yang sempit (Khaledian, 2013). Seluruh indikator keterampilan sosial terimplikasi melalui kegiatan diskusi, presentasi dan laporan kegiatan. Pembelajaran kontekstual dapat meningkatkan keterampilan sosial melalui model pembelajaran inkuiri sosial.

Pembelajaran inkuiri sosial membutuhkan fakta sebagai konsep pendukung untuk dipelajari (Gunckel, 2010; Callahan, et al, 1991; Sutman, et al, 2007). Fakta sebaiknya mengedepankan rasa keingintahuan sebagai pendukung untuk menyelesaikan masalah (Kulthau et al, 2007; Shanaban, 2010). Pembelajaran inkuiri sosial melatih siswa untuk meningkatkan keterampilan sosial. Inkuiri sosial mengajak siswa untuk berinteraksi satu dengan yang lainya agar memperoleh kemampuan yang hampir sama. Hal tersebut sesuai dengan hasil penelitian yang sudah dilakukan oleh Anita (2017) yaitu ada pengaruh pembelajaran inkuiri sosial terhadap keterampilan sosial. Penelitian dilakukan dengan menggunakan sampel sebanyak 211 responden.

Berdasarkan latar masalah di atas, tujuan penulisan artikel ini untuk mengetahui pengaruh pengaruh kecerdasan adversitas dan kecerdasan emosional melalui inkuiri sosial terhadap keterampilan sosial siswa.

\section{METODE}

Penelitian ini menggunakan metode ex post facto. Metode ex post facto merupakan penelitian yang menunjukan perlakuan yang sudah terjadi pada variabel bebas, sehingga variabel bebas tersebut tidak diberikan perlakuan. Sedangkan variabel terikat dilihat dari efek yang diberikan oleh variabel bebas. Tujuan penelitian ini yaitu untuk mengetahui pengaruh kecerdasan adversitas dan kecerdasan emosional melalui inkuiri sosial terhadap keterampilan sosial siswa. Analisis data menggunakan statistik deskriptif. Populasi yang digunakan dalam penelitian ini adalah siswa kelas VIII SMP Negeri 10 Bandar Lampung yang berjumlah 140 siswa. Sampel penelitian menggunakan teknik simple random sampling. Penentuan jumlah sampel menggunakan rumus slovin berjumlah 104 siswa.

Variabel penelitian terdiri dari variabel eksogen, varaibel endogen, dan variabel intervening. Variabel yang bertindak sebagai eksogen yaitu kecerdasan adversitas $\left(\mathrm{X}_{1}\right)$ dan kecerdasan emosional $\left(\mathrm{X}_{2}\right)$. Sedangkan model inkuiri sosial $(\mathrm{Y})$ bertindak sebagai variabel endogen. Selanjutnya keterampilan sosial $(Z)$ sebagai variabel intervening.

Teknik pengumpulan data menggunakan kuesioner yang disesuaikan dengan variabel yang akan diteliti. Kuesioner didesain semudah mungkin agar responden mudah untuk memahami. Kuesioner yang akan digunakan sebelumnya dilakukan uji validitas dan uji reliabilitas. Jika 
kuesioner sudah valid dan reliabel tahap selanjutnya yaitu kuesioner dibagiakn kepada responden yang dijadikan sampel penelitian.

Setelah data terkumpulkan tahap selanjutnya yaitu menganalisis data tersebut. Data di analisis menggunakan Structural Equation Modelling (SEM). Untuk mengetahui pengaruh langsung maupun tidak langsung antar variabel. Analisis ini berkaitan dengan pengaruh antar variabel endogen, eksogen, dan intervening. Selanjutnya dimasukan ke persamaan struktural dan pengukuran analisis jalur (path analysis).

\section{HASIL DAN PEMBAHASAN}

Hasil penelitian menunjukan pengaruh antar variabel eksogen, endogen, dan intervening baik secara langsung maupun tidak langsung. Hasil penelitian dianalisis menggunakan analisis Structural Equation Modeling (SEM). Responden yang dijadikan sebagai sampel penelitian yaitu siswa kelas VIII SMP Negeri 10 Bandar Lampung yang berjumlah 104 siswa. Tujuan penelitian ini untuk mengetahui pengaruh kecerdasan adversitas dan kecerdasan emosional melalui model inkuiri sosial terhadap keterampilan sosial.

Merujuk pada tujuan penelitian, maka ditetapkan 4 (empat) rumusan masalah. Hipotesis di uji menggunakan uji parsial dan uji simultan. Rumusan masalahnya antara lain (1) pengaruh kecerdasan adversitas terhadap keterampilan sosial, (2) pengaruh kecerdasan emosional terhadap keterampilan sosial, (3) pengaruh kecerdasan adversitas melalui model inkuiri sosial terhadap keterampilan sosial, (4) pengaruh kecerdasan emosional melalui model inkuiri sosial terhadap keterampilan sosial.

Data sampel berjumlah 104 siswa. Secara umum data menunjukan bahwa kondisi variabel kecerdasan adversitas dalam kategori sedang atau cukup baik, variabel kecerdasan emosional dalam kategori sedang atau cukup baik, variabel model inkuiri sosial dalam kategori baik, dan variabel keterampilan sosial siswa dalam kategori cukup baik,

Pengujian hipotesis menggunakan software SPSS untuk menemukan model struktural Structural Equation Modeling (SEM). Hasil uji hipotesis dapat dilihat pada model stuktural pada gambar 1.

Kecerdasan adversitas dan kecerdasan emosional turut andil dalam pembentukan keterampilan sosial seseorang. Kecerdasan emosional didukung dengan kecerdasan adversitas akan membuat individu tidak hanya mampu mengenali perasaan diri sendiri dan orang lain, tetapi juga mampu meningkatkan motivasi diri secara keseluruhan untuk mencapai kesuksesan dan prestasi akademik (Wibowo, 2015). Kecerdasan emosional dan kecerdasan adversitas mempunyai peranan penting dalam kehidupan siswa. Hal tersebut akan berdampak sebagai faktor pendukung siswa dalam mencapai kesuksesan dalam belajar (Wardani, 2014).

Hasil penelitian menunjukkan bahwa kecerdasan emosional dan kecerdasan adversitas dalam kategori sedang atau cukup baik. Hal yang menentukan kesuksesan seseorang bukan kecerdasan intelektual, tetapi lebih pada kecerdasan adversitas dan kecerdasan emosional (Prawitasari, 1998). Dianggap bahwa kecerdasan otak bergantung pada faktor genetik dan sulit untuk diubah, namun tidak demikian dengan kecerdasan adversitas dan kecerdasan emosional yang dapat diubah untuk meraih sukses kehidupan. Hal tersebut selaras dengan pendapat Golemen (dalam Theda, 2018) yang menyatakan bahwa kecerdasan intelektual yang sering disebut dengan IQ merupakan kecerdasan yang dibangun oleh otak kiri. Kecerdasan intelektual (Apriyanti, 2014; Choiriah, 2013; Floretta, 2014) hanya mampu menyumbang 20 persen 
kesuksesan dan 80 persen berasal dari kekuatan-kekuatan lain termasuk kecerdasan adversitas dan kecerdasan emosional. Kecerdasan intelektual dibutuhkan untuk melakukan aktivitas mental berpikir, menalar, dan memecahkan masalah. Sedangkan kecerdasan adversitas dan kecerdasan emosional dibutuhkan seseorang agar mampu mengenali perasaan diri sendiri dan orang lain serta mampu mengelola emosi (Husnurrosyah, 2015).

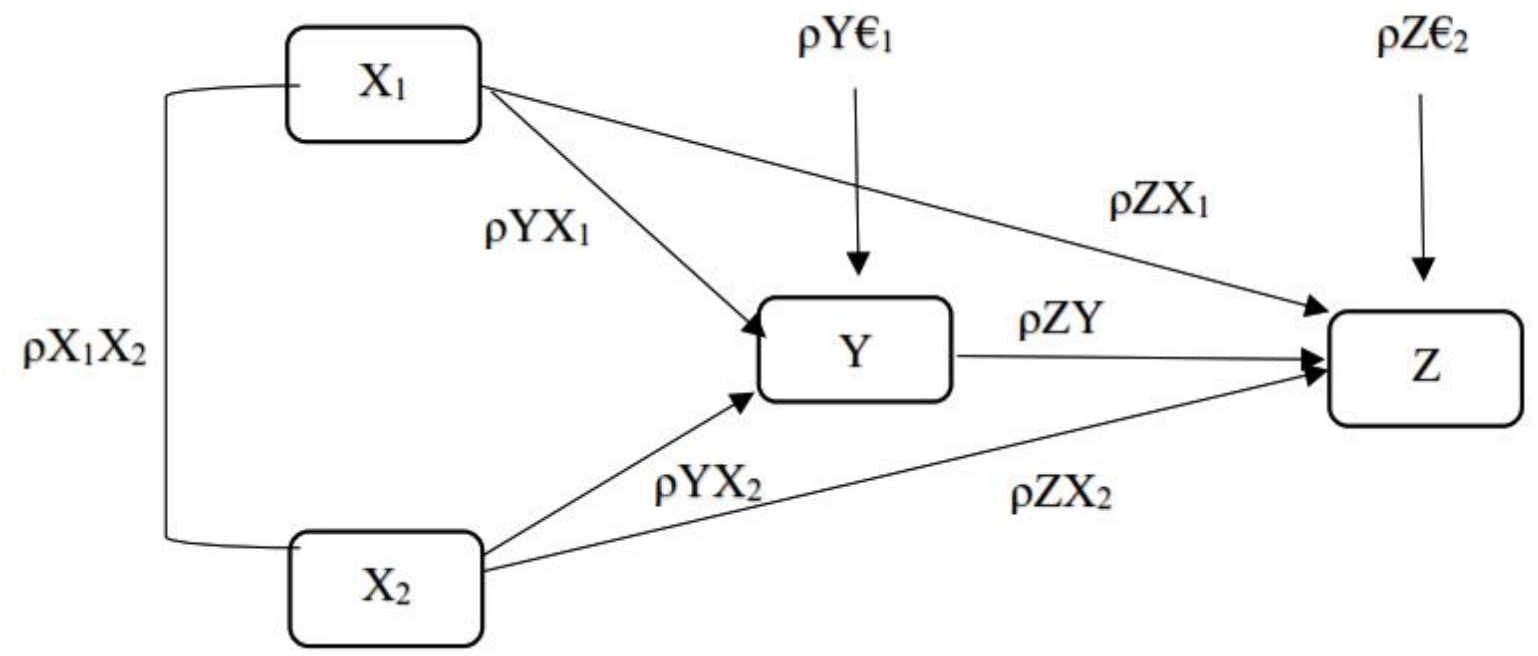

Gambar 1. Model Struktural

\section{Keterangan:}

$\mathrm{X}_{1} \quad=$ Kecerdasan Adversitas

$\mathrm{X}_{2} \quad=$ Kecerdasan Emosional

$\mathrm{Y} \quad=$ Model Inkuiri Sosial

$\mathrm{Z} \quad=$ Keterampilan Sosial

$\rho \mathrm{YX}_{1}=$ Koefisien Jalur $\mathrm{X}_{1}$ terhadap $\mathrm{Y}$

$\rho \mathrm{YX}_{2}=$ Koefisien Jalur $\mathrm{X}_{2}$ terhadap $\mathrm{Y}$

$\rho Z Y=$ Koefisien Jalur $Z$ terhadap $Y$

$\rho Z X_{1}=$ Koefisien Jalur $Z$ terhadap $X_{1}$

$\rho \mathrm{ZX}_{2} \quad=$ Koefisien Jalur $Z$ terhadap $X_{2}$

$\rho X_{1} X_{2}=$ Koefisien Jalur $X_{1}$ terhadap $X_{2}$

$\rho €_{1} \quad=$ Koefisien Jalur Variabel Lain terhadap Y di Luar Variabel X

$\rho Z €_{2}=$ Koefisien Jalur Variabel Lain terhadap Z di Luar Variabel X dan Y

\section{Data Hasil Analisis}

$\begin{array}{ll}\rho \mathrm{YX}_{1} & =0,243 \\ \rho \mathrm{YX}_{2} & =0,324 \\ \rho \mathrm{ZY} & =0,432 \\ \rho \mathrm{ZX}_{1} & =0,213 \\ \rho \mathrm{ZX}_{2} & =0,876 \\ \rho X_{1} \mathrm{X}_{2} & =0,435 \\ \rho \epsilon_{1} & =0,213 \\ \rho Z \epsilon_{2} & =0,134\end{array}$

Seseorang yang memiliki kecerdasan emosional dan kecerdasan adversitas tinggi akan memiliki kemampuan yang lebih baik dalam melaksanakan dan menyelesaikan tugas. Semakin tinggi sesorang memiliki kedua kecerdasan tersebut akan lebih efektif menyelesaikan tugas. Kemampunya tersebut menjad modal yang sangat penting guna mencapai kesuksesanya di masa yang akan datang. Seseorang yang memiliki kecerdasan emosional dan kecerdasan 
adversitas tinggi menganggap kesulitan dan tantangan sebagai alat untuk meningkatkan potesi diri (Zainudin, 2011).

Apabila seseorang sudah memiliki kecerdasan adversitas dan kecerdasan emosional yang baik, maka untuk menghantarkan agar siswa memiliki keterampilan sosial yang baik pula ada peran inkuiri sosial. Maka, model inkuiri sosial memiliki peranan yang penting untuk menghantarkan kecerdasan adversitas dan kecerdasan emosional menjadi keterampilan sosial.

Model inkuri sosial mempunyai tahapan yang selaras untuk membuat pengelaman siswa dalam membentuk ketarampilan siswa. Melalui model inkuiri sosial, kecerdasan adversitas dan kecerdasan emosial akan berperan efektif dalam meningkatkan keterampilan sosial. Hal tersbut akan berguna bagi siswa untuk kesuksesan belajar di kelas dan di masa yang akan datang.

\section{SIMPULAN}

Berdasarkan hasil penelitian menunjukan bahwa variabel eksogen, variabel endogen, dan variabel intervening saling berkaitan. Melalui model inkuiri sosial, kecerdasan adversitas dan kecerdasan emosial akan berperan efektif dalam meningkatkan keterampilan sosial. Hal tersbut akan berguna bagi siswa untuk kesuksesan belajar di kelas dan di masa yang akan datang. Diharapkan sekolah dapat mengoptimalkan kecerdasan adversitas dan kecerdasan emosial agar dapat meningkatkan keterampilan sosial dan keterampilan akademik siswa. Tindakan-tindakan dibutuhkan selain untuk meningkatkan mutu pembelajaran juga sebagai pengembangan diri dan karakter siswa.

\section{DAFTAR PUSTAKA}

Anita, Rahmawaty. 2017. Pengaruh Pembelajaran Inkuiri Sosial Terhadap Keterampilan Sosial. Jurnal Akuntansi, Vol. XX. No. 01. September 2017.

Apriyanti. 2014. Pengaruh Kecerdasan Emosional, Kecerdasan Spiritual dan Perilaku Etis terhadap Kinerja Auditor Pemerintah. JOM Fekon, Vol. 1 Nomor 2 Oktober 2018.

Ardana, I Cenik. 2013. Kecerdasan Intelektual, Kecerdasan Emosional, Kecerdasan Spiritual, dan Kesehatan Fisik untuk Memprediksi Prestasi Belajar Mahasiswa Akuntansi. Jurnal Akuntansi, Vol. XVII. No. 03. September 2013.

Budiani, I. A. P., Dantes, N., \& Dantes, K. R. 2014. Pengaruh Kecerdasan Emosional dan Adversity Quotient terhadap Sikap Profesional Ditinjau dari Status Profesi Guru SMP Di Kecamatan Buleleng Kabupaten Buleleng. E-Journal Program Pascasarjana Univeristas Pendidikan Ganesha, Vol 4

Callahan, J.F., Clark, L.h., Kellough, R.d. 1991. Teaching In The Middle and Secondary School. USA: Macmilan Publishing Company. A Year of Inquiry (Edited by Linda Froschauer). USA: NSTA. Pp:24-26.

Choiriah, Anis. 2013.Pengaruh Kecerdasan Emosional, Kecerdasan Intelektual, Kecerdasan Spiritual, dan Etika Profesi terhadap Kinerja Auditor dalam Kantor Akuntan Publik (Studi Empiris pada Auditor dalam Kantor Akuntan Publik Di Kota Padang dan Pekanbaru). Jurnal Universitas Negeri Padang, Padang.

Depdinas. 2007. Konsep Pengembangan Model Integrasi Kurikulum Pendidikan Kecakapan Hidup. Pendidikan Menengah. Jakarta: Badan Penelitian dan Pengembangan Pusat Kurikulum.

Floretta, Gabritha. 2014. Pengaruh Kecerdasan Emosional, Kecerdasan Spiritual dan Etika 
Profesi terhadap Kinerja Auditor pada Kantor Akuntan Publik DKI Jakarta. Jurnal Binus University

Gitosaroso, Moh. 2012. Kecerdasan Emosi (Emotional Inteleligence) dalam Tasawuf. Jurnal Katulistiwa-Journal of Islamic Studies Vol. 2 No. 2

Gunckel, KL. 2010. Make School Science More Like Scientist' Science. Science Childen A Year of Inquiry. Volume 48. Number 1. America: National Science Teacher Association. Delta Education. P47-51.

Hartosujono. 2015. Perilaku Adversity Quotient Mahasiswa Ditinjau dari Locus Of Control. Jurnal Sosiohumaniora Vol. 1 No. 1 April 2015.

Husnurrosyidah. 2015. Pengaruh Kecerdasan Emosional dan Kecerdasan Spiritual terhadap Pemahaman Akuntansi Syariah dan Kecerdasan Adversitas sebagai Variabel Mediasi. Jurnal Equilibrium Jurnal Ekonomi Syariah. Vol. 3 No. 2 Desember 2015.

Khaledian. 2013. The Relationship Between Accounting Students Emotional Intelligence (EQ) and Test Anxienty and Also Their Academic Achievement. European Journal of Experimental Biology Pelagia Research Library. ISSN: 2248-9215 Coden (Usa): Ejebau.

Karimah, Ummah. 2017. Pengaruh Iklim Pondok Pesantren terhadap Kecerdasan Adversitas Santri. Jurnal Fokus Konseling, Vol. 3 Nomor 2 Tahun 2017.

Kulthau, CC. 2010. Guded Inquiry: School Libraries in The 21 Century. School Libraries Wordwide. Volume 16, Number 1, 17-28.

Lwin M., Kho A., Lyen, K., Sim C. 2008. Cara Mengembangkan Berbagai Komponen Kecerdasan. Petunjuk Praktis Bagi Guru, Masyarakat dan Orang Tua. Indonesia: PT Macanan jaya Cemerlang.

Prawitasari, Johana E. 1998. Kecerdasan Emosi. Buletin Psikologi No. 1 Hal 21-31

Salam, Rudi. 2017. Model Pembelajaran Inkuiri Sosial dalam Pembelajaran IPS. Jurnal Harmoni Vol. 2 No. 3

Schoon, I., Parsons., \& Sacker, A. 2004. Socioeconomic adversity, educational resilience, and subsquent levels of adult adaption. Journal of Adolescent Research. Vol 19 No 4.

Scott, C., Tomasek, T and Matthews, CE. 2010. Thingking Like a Scienttist! Science Childen A Year of Inquiry. Volume 48. Number 2. America: National Science teacher Association. Delta Education. P.38-42.

Shanaban, M.C. 2010. Reading As Scientist: Student Evaluate The Quality Of Scientific Study. Science Childen A Year of Inquiry. Volume 48. Number 1. America: National Science Teacher Association. Delta education. P.54-58.

Shivinder dan Kaur. 2012. Adversity Quotient: A New Paradigm to Explore, Journal, International Journal of Contemporary Business Studies. Vol. 3 No. 4

Sutman, FX., Schuckler, JS., Woodfield, YD. 2008. The Science Quest. Using Inqury/Discovery To Enhance Student Learning. San Francisco; Jossey-Bass.

Theda, Rio Surya Wijaya. 2018. Pengaruh kecerdasan Intelektual, Kecerdasan Emosional, dan Kecerdasan Spiritual Pemilik pada Kinerja Usaha Micro kecil Menengah. E-Jurnal Akuntansi Universitas Udayana. ISSN: 2302-8556 Vol. 25 No. 2 November 2018.

Usman, M.U. 2009. Menjadi Guru Profesional. Bandung: Penerbit PT Remaja Rosdakarya 
Volume 4 Nomor 2, Oktober 2019: hal 66 - 73

Wahab, AA. 2007. Metode dan Model-Model Mengajar IPS. Bandung: Alfabeta.

Wardani, Wardani. 2014. Pengembangan Model Webquest pada Mata Pelajaran IPS Di Sekolah Menengah Kejuruan. Jurnal Studi Sosial Vol. 2 No. 1

Wibowo, Moersito Wimbo. 2015. Hubungan antara kecerdasan Emosi, Adversity Quotient dan Efikasi Diri pada Siswa Kelas VII Madrasah Aliyah Negeri 1 Magelang.

Wijayanti, Gersontan Lewi. 2012. Peran Kecerdasan Emosional dan Kecerdasan Spiritual dalam Meningkatkan Kinerja Auditor. Dalam Jurnal Ilmiah Mahasiswa Akuntansi Vol. 1 No. 2

Zaim, Muhammad. 2016. Pendidikan Anak dalam Pengembangan Kecerdasan IQ, EQ, dan SQ (Studi Kitab Tuhfat Al-Mawdud Bi Ahkam Al-Mawlud Karya Ibnu Al-Qayyim Al Jauziyah).

Zainuddin. 2011. Pentingnya Adversity Quotient dalam Meraih Prestasi Belajar. Jurnal guru Membangun Vol. 26. No. 2 